\title{
LEGIBILITY
}

A major purpose of the Technical Information Center is to provide the broadest dissemination possible of information contained in DOE's Research and Development Reports to business, industry, the academic community, and federal, state and local governments.

Although a small portion of this report is not reproducible, it is being made available to expedite the availability of information on the research discussed herein.

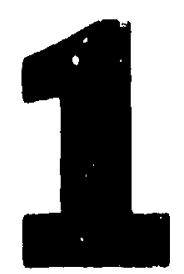


LA-UR-87-1517

\section{L.Niv $87042-1$}

TITLE: "Superlattice Geometry for Gamma-Ray Lasers"

mamitreo ro: American Physical Soc1ty, Cryatal City, VA, meeting, Apr 11 20-23, 1987

LA-UR--87-1517

Authop(9): G. C. Baldwin, P-3

DE87 010103

Los Alamos National Laboratory

Los Alamos, NM 87545

\section{DISCLAIMER}

This roport wes properal at an account of work aponeored by an asency of the United Statea Government. Nelther the Unitod Situtes Government nor any agency thereof, nor any of their omployees, makes any warranty, expreas of impiled, or asaumes any lojal liability of rosponal. billity for the sexuracy, completeneas, or usefulnese of any information, apparatus, product, or process dictosed, of repravents that lits use would not infringe privatoly ownod rights. Refor. ence hereln to any upecific commercial producl, procesu, of service by trade name, Irademark,

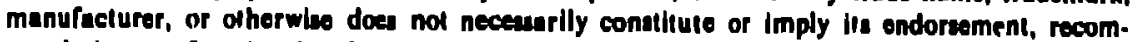
mendation, of favorins by the United States Covornment of any agency thereor, The viowe and opintons of authore expreseed herein do not necesenrlly stute or reflect thom of the United Stales Covernment or any agoncy thereof. 


\author{
SUPERLATTICE GEOMETRY FOR GAMMA-RAY LASERS* \\ G. C. Baldwin \\ Physics Division \\ Los Alamos National Laboratory \\ Los Alamos NM 37545
}

\begin{abstract}
The central problem to developing a graser--that pumping can inhibit or destroy the Mossbauer and Borrmann effects--can concelvably be mitigated by a superlattice geometry, into which collimated coherent tzansfer radiation is introduced to form a multiwave Borrmann (or antiBorrmann) mode. This could also overcome the limitations of cooperation length and Fresnel number that otherwise restrict the size and performance of a superradiant graser.
\end{abstract}

INTRODUCTION

\title{
Conceptual single-crystal arasers
}

Recent articles ${ }^{1-3}$ have described hypothetical grase: systems in which a nuclear fopulation inversion is suddenly established by interlevel transfer from a long-11ved isomerlc state to another level in that nuclide, followed by a recollless ("Mossbauer") gamma-ray transition. The graser body is a single-crystal host into which the active isomer has been Incorporated substitutionally, so that wave modes can be established by Bragg-reflection that couple strongly to nuclear multipolss higher than electric dipole, but couple only weakly to aromic alectrons. ${ }^{2}$ It was shown in Reference 1 that, if the grauer body is in the form of a cylinder or prism a few $\mathrm{mm}$ long with near-unity Fresnel number, doped with at least $10^{12}$ leomeric nuclel, superradiance 4 should ovolve within a short time after the tranefor step, hopefully before 10se of crystal stucture. To prevent premature dissolution of the graser crystal, however, the transfor procese must be, not only rapid, but extremely efficlent. We shall therefore asesune heroln that it w11l. require a sharply tuned, monochromatic beam of coherent radiation,

\section{MASTER}


although we make no attempt here to identify a particular mechanism by which transfer is effected.

Wave modes of the ramma radiation

Bragg-reflection of gamma radiation in the primary lattice creates a superposition of Borrmann and anti-Borrmann modes. 5 Borrmann ("B") modes, having vanishing electric Eleld amplitude at the lattice sites, interact only weakly with electril dipoles (atoms), but strongly with higher multipoles (most nuclei) near lattice sites; the converse is true for the anti-Borrmann ("A") mode Coupling coefficients of $B$ modes to various multipoles have been derlved by Hutton, Harinon and Tramme1.. 6 The coupling coefficient of a B mode to an electri: dipole contains as a factor the mean square displacement from the ideal lattice plane, ${ }^{5}$ so that the $B$ mode is absorbed only weakly by the atoms, but it can be amplified by "anomalous" stimulated emission ${ }^{6}$ from magnetic dipole or higher multipolarity transitions in the nuclei; the A mode is strongly absorbed by atoms at lattice sites. ${ }^{5}$ Explolting the Borrmann effect greatly reduces the threshold excitation requirement and increases the lasing gain for a given level of excitation above threshold. ${ }^{5}$ The several Bragg-reflected waves that interfere cooperatively within the crystal emerge as separated beams.

\section{Limitations on sraser performance}

If the transfer pump is to 11 luninate the ontire graser body simultaneously, the length of the graser cannot exceed the cooperation length for superradiance, 6 and its diameter is olso limited by tho Fresnel-number constralnt; otherwise, the entire syctem will not emlt as a coherent unit. ${ }^{3}$ These two constraints on graser volume $1 \mathrm{~m} 1 \mathrm{t}$ the Intensity that can be generated. If, as well, the grasor body $1 \mathrm{~s}$ 1solated, Its temparature will riso rapldly, becauss of lts small heat. capacity, Inhlblting the Mossbauer procesa.

However, the delivery of the tranefar pulso and the attendant. neating wore not addrassed in Refuronces 1-3. This paper enlarges upon an earlier proposal 2,8 for a way to licrease the effictency of the transfer step, thereby to rocluce t to heating offect, whils avolding 
restrictions on the energy that can be released coherently in superradiance.

THE SUPERLATTICE CONCEPT

\section{Proposed geometry}

Assume that the transfer radiation is a intense, coherent and well collimated electromagnetic wave of wavelength $\lambda$. It is propossed 8 to construct the graser by doping an extended host crystal with the storage isomer so as to form a two-dimensional lattice of linear regions (See Figure 1), each having dimensions typical of a single graser body. The transfer radiation, of wavelength $\Lambda$, is to be introduced as a multiple array of beams, each well collimated (as at the focal waist of a laser beam) at appropriate angles, to be specifled below. Figure 2 illustrates four beams of transfer radiation incident at the Bragg angle upon the macroscopic superlattice.

\section{Superlattice parameters}

For defiriteness, each of the citive regions is assimed to be a long rectlinear paralleleplped, substitutionally doped with storage isomer, so that its internal crystal structure is a continuation of that of the undoped host, which, again for definiteness, is assumed to have simple cublc symmetry, the graser axes lying in the 116 direction. Let the lattice constant of the primary, host crystal be a; that of the two. dimensional array of doped ("graser") reglons, $d$. Lec the cross sections of the active regions be squares of side b. Assume that the doped reglons have different scattering power and greater absorption than the intervening undoped reglons of the host.

First, consider the relationehip of d to a. Clearly, d will be an integor multiple of a (a large integer if $\Lambda$ is an optical wavelangth). In order that the soveral beams of tranefer radiation ontering the superlattice can Interfore to establiah a multiwave Bragg-reflected mode ${ }^{6}$ with nearly the same cone angle and multipliclty as that of the gamma radiation to be etimulated in the primary lattice, the ratio a/d of primary-to-superlattice spacings should (approxlmately.-subject to 
the integer constraint) equal that of graser-to-transfer wavelengths $\lambda / \Lambda$ within the crystal. Transfer and gamma radiations then will have the same Bragg angles in their respective lattices and propagate parallel to the line of intersection of the reflecting planes at approximately equal velocities (except, of course, for dispersion). With swept excitation, the restriction of cooperation length ${ }^{1}$ is avoided. Corresponding points in all active regions are pumped simultaneously, ensuring synchronism and, possibly, coherence among their respective output beams.

Wave modes of the transfer radiation

Figure 2 iliustrates the directions and polarizations of fuur transfer beams. Table I shows the relationships of the external beams to the two principal wave modes they establish by Bragg reflections within the superlattice. For the B mode, the electric (but not the magnetic!) vector vanishes at each plane passing through the centers of doped (reflecting) reglons. The electric vector of the confugate, A mode is maximum at those planes. The Poynting vector $\mathbf{S}$ is parallel to and either vanishing or maximum, respectively, at the axes of the doped reglons.

Therefore, depending upon how the incldent beams are phased, there are two possibilities for the transfer radiation within the superlattıce.

Assume first that the transfer step requires a direct interaction

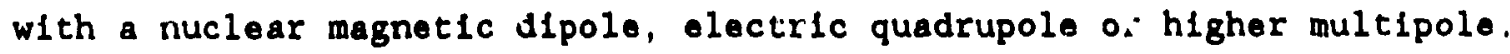
The $B$ mode of the transfer radiation, with enhanced nuclear but reduced electronic interaction, is the effective mode; vanishing of 1 ts Poynting flux mitigates heating in the doped reglons. If it proves possible to control the relative phases of the paired beams of transfer radiation, no transition rogion contalning the unwanted $A$ mode will be prosent; otherwise, as in the gamma-ray case, the A mode will rapidly atcenuate. Although tize fleld amplitude in the undoped regions exceeds that in the doped regions, the increased coupling to the nuclear transition reduces the demand for transfer power and, therefore, further reduces the heating in the foped rogions. The mean square extension of the doped 
material from the centers of the superlattice here corresponds to the negative logarithm of the Debye-Waller factor of the gamma-ray case.

Alternatively, suppose that the transfer process is indirect, first requiring an electric dipole interaction. For example, one postulated mechanism ${ }^{8}$ for transfer involves exciting a collective dipole oscillation of the electronic shells that channels energy to the nucleus via a nonlinear near-field interaction. ${ }^{9}$ The anti-Borrmann is then the preferred mode. In that case, wave interference increases the amplitude of the electric vector of the transfer radiation at the doped regions, and so, reduces both the power required of the transfer pulse and the heating in the undoped regions, facilitating their roles as heat sinks.

\section{HEAT TRANSFER}

Exac: analysis of the thermal effect of the transfer pump in an actual graser superlattice awaits specification of the active and host materials, of the transfer radiation and its mode of interaction, of the cone angle and wave-mode multiplicity, absorption coefficients for both radiations in boch doped and and undoped host, etc.

In the absence of such information, we consider a hypothetical case that 1llustrates the potential advantages of a superlattice geometry. The source regions are assumed to have the dimensions given In Table II and to be heated by absorption of the transfer flux given therein. Assume that the doped regions are the principal heat sources and neglect heat generation in the undopad reglons of the host, which has the properties listed in Table II.

Assume that the cross sections of the active regions are squares of side $b \leq 0.1 d$, with energy-absorption coefficinnt $\mu \mathrm{cm}^{-1}$. Let each of the four transfor beams be a suare-wave pulse of power density $P W$ $\mathrm{cm}^{-2}$, lasting for $\Delta t$, and be incldent at ine Bragg angle $\theta$. Assume further that the hos is relatively transparent to the transfor radiation.

Then the heat deposited per unit langth in each doped region of the superiattice is 


$$
Q_{1}=\Delta t \int_{-d / 2}^{d / 2} \int_{-d / 2}^{d / 2} \mu(x, y) s_{i}(x, y) d x d y, \quad 1-A, B
$$

approximately

$$
Q_{A}=4 P \Delta t \mu \cos \theta b^{2}\left(2-\frac{\pi^{2} b^{2}}{6 d^{2}}\right)
$$

and

$$
Q_{I i}=\frac{4 P \Delta t \mu \cos \theta \pi^{2} b^{4}}{6 d^{2}}
$$

because the transveise dimensions of each source region are small compared with their separations.

To obtain an app:oximate value for the t3mperature dependence at specifled points in this superlattice cell, we can therefore apply the well-known formula for the rise in temperature at a point $I$ at the time $t$ after a sudden generation of heat in an infinite line source located at $\Sigma_{0}, 10$

$$
\Delta T-T_{0} \exp \left\{\frac{-\left|I-I_{0}\right|^{2}}{4 \pi t}\right\}
$$

where

$$
\begin{aligned}
T_{0} & =\frac{Q}{4 \pi \kappa C t} \\
t & =\text { diffusivity } \\
C & =\text { heat capccicy per unit volume }
\end{aligned}
$$


in which $x$ is the diffusivity, $c$ is the heat capacity per unit volume of the doped crystal.

Applied to an infinite two-dimensional square superlattice of line sources located at the points

$$
x_{0}=m d, \quad y_{0}=n d ; n, m-\ldots-2,-1,0,1,2 \ldots
$$

this gives the formula

$$
\Delta T-\frac{Q}{4 \pi \kappa C t} \sum_{m=-\infty}^{\infty} \sum_{n=-\infty}^{\infty} \exp \left\{\frac{x-m d)^{2}}{4 \kappa \tau}\right\} \exp \left\{\frac{y-n d)^{2}}{4 \pi t}\right\}
$$

which takes the speclal forn

$$
\Delta T\left(\frac{d}{2}, \frac{d}{2}\right)-\frac{Q}{4 \pi \kappa C t} \operatorname{ext}\left\{-\frac{d^{2}}{8 \pi t}\right\} \sum_{m} \sum_{n} \exp \left\{-\frac{\left(m^{2}+n^{2}\right) d^{2}}{4 \pi t}\right\}
$$

at the cell centers $(e .8, x, y-d / 2)$ and

$$
\Delta T(0,0)-\frac{9}{4 \pi n} \overline{C t} \sum_{m} \sum_{n} \exp \left\{-\frac{\left(m^{2}+n^{2}\right) d^{2}}{4 x t}\right\}
$$

at the cell corners (e. $2, x, y-0$, midlines of doped, active reglons).

The indicated serles converge rapidly and are readlly ovaluated on a small computer, using spreadsheet software. Figures 3 and 4 show results for the case of Table II.

COMENTS

For parameters of the magnitudes assumed in the example, thermal relaxation to temperatures that allow the Mossbauer effect to recover before dissolution of the cryatal ${ }^{12}$ and $10 s$ of poptiation inversion by 
decay is possible. Of nourse, these numbers may not be realistic, especially the neglect of host absorption. Alternatively, one can use this approximate calculation to establish limiting values for the system parameters.

This demonstrates that a superlattice geometry could have the following advantages:

1) reducing the intensity of the transfer source that is needed for a given transfer rate;

2) providing a heat sink;

3) circumventing restrictions on the amount of graser material that would otherwise be imposed by the requirements of coherence.

This example has treated a four-wave case for simplicity. A still simpler, more easily corstructed geometry, using a layered host and ordinary two-wave Bragg reflections, would also have some advantage. Higher multiplicity would give even greater advantages in reducing transfer and increasing output requirements and is, of course, possible. For example, Hutton has pointed out that a six-beam wave mode can couple well to electric octupole transitions. ${ }^{6}$ Introduction of any number of beams of transfer radiation at a common cone angle can be accomplished by means of a conical lens ${ }^{13}$ or mirror; the transfer radiation pulse will advance along the graser axis as a traveling-wave.

However, strict collimation, monochromaticlty, coherence, and low hust absorption of the transfer radiation are essential. The possibility of preparing such a structure will depend strongly on the physical, chemical and crystallographic properties of the host and dopant as well as the nuclear properties.

The effect of interactions among the varlous regions on the kinetics and coherence of the superradiant emission frow the superlattice system requires further study. 


\section{ACKNOWLEDGMENTS}

The author gratefully acknowledges useful discussions with Peggy Dyer, Timothy Hutton, Johndale Solem and George Trammell, and financial support by the IST/SDIO. 
REFERENCES :

*Work supported by IST/SDIO and administered by NRL.

1. G. C. Baldwin and M. S. Feld, J. Appl. Phys. 53, 3669 (1986).

2. G. C. Baldwin, M. S. Feld, J. T. Hutton, J. P. Hannon and G. T. Tramme11, J. de Physique 47, C-6-299 (1986).

3. C. B. Collins in AIP Conf. Proc. 146, 18-21, W. Stwalley and $M$. Lapp, editors, Amer. Inst. of Phys. (1985).

4. J. C. MacGillivray and M. S. Feld in Topics in Current Physics 20, $7-57$ (1980).

5. B. Batterman and H. Cole, Rev. Mod. Phys. 36, 681-717 (1964).

6. J. T. Hutton, Ph. D. Thesis, Rice University (1986); J. P. Hannon and G. T. Trammel1, Opt. Comm. 15, 320-334 (1975).

7. F. T. Arecch1 and E. Courtens, Phys. Rev. A2, 1730-1737 (1970).

8. G. C. Baldwin, in AIP Conf. Proc. 146, 6-10 (1985).

9. J. C. Solem, ibid, 22-25; G. A. Rinker, ibid, 48-49.

10. L. C. Biedenharn, G. C. Baldwin, K. Boyer and J. C. Solem, ibid, $52-53$; L. C. Biedenharn, Bull. Amer. Phys. Soc. 32, 1043 (I987).

11. H. S. Carslaw and J. C. Jaeger, Conduction of Heat In Solids, 2nd edition, Section 103, Oxford Press (1959).

12. G. Mourou, private communication; see also Report DOE/DP/40200-05, University of Rochester, $196-203$ (1986).

13. F. P. Schafer, in "X-Ray Lasers," P.149-150, loc. cit. 


\section{FIGURES}

1. Proposed superlattice geometry for gamma-ray lasers: a large single-crystal host in which the active material is disposed in a regular arxay of linear reglons, formirg a set of parallel graser bodies, each of unity Fresnel number. In this case, a square array is depicted; other geometries (e.g., hexagonal) are possible.

2. Diagram 1llustrating the introduction of four beams of transfer radiation incldent at the Bragg angle on a graser siperlattice. Propagation $\left(k_{1}\right)$ and polarization $\left(E_{1}\right)$ vectors are indicated.

3. Temperature rise et the graser regions and at the center of a superlattice cell, as a function of time after a transfer pulse in a Borrmann mode, calculated using the data of Table II and Equation 6 .

4. Temperature rise at the graser zegions and at the center of a superlattice cell, as a function of time after a transfer pulse in an antiBorrmann mode, calculated using the data of Table II and Equation 6. 


\section{GRASER SUPERLATTICE}

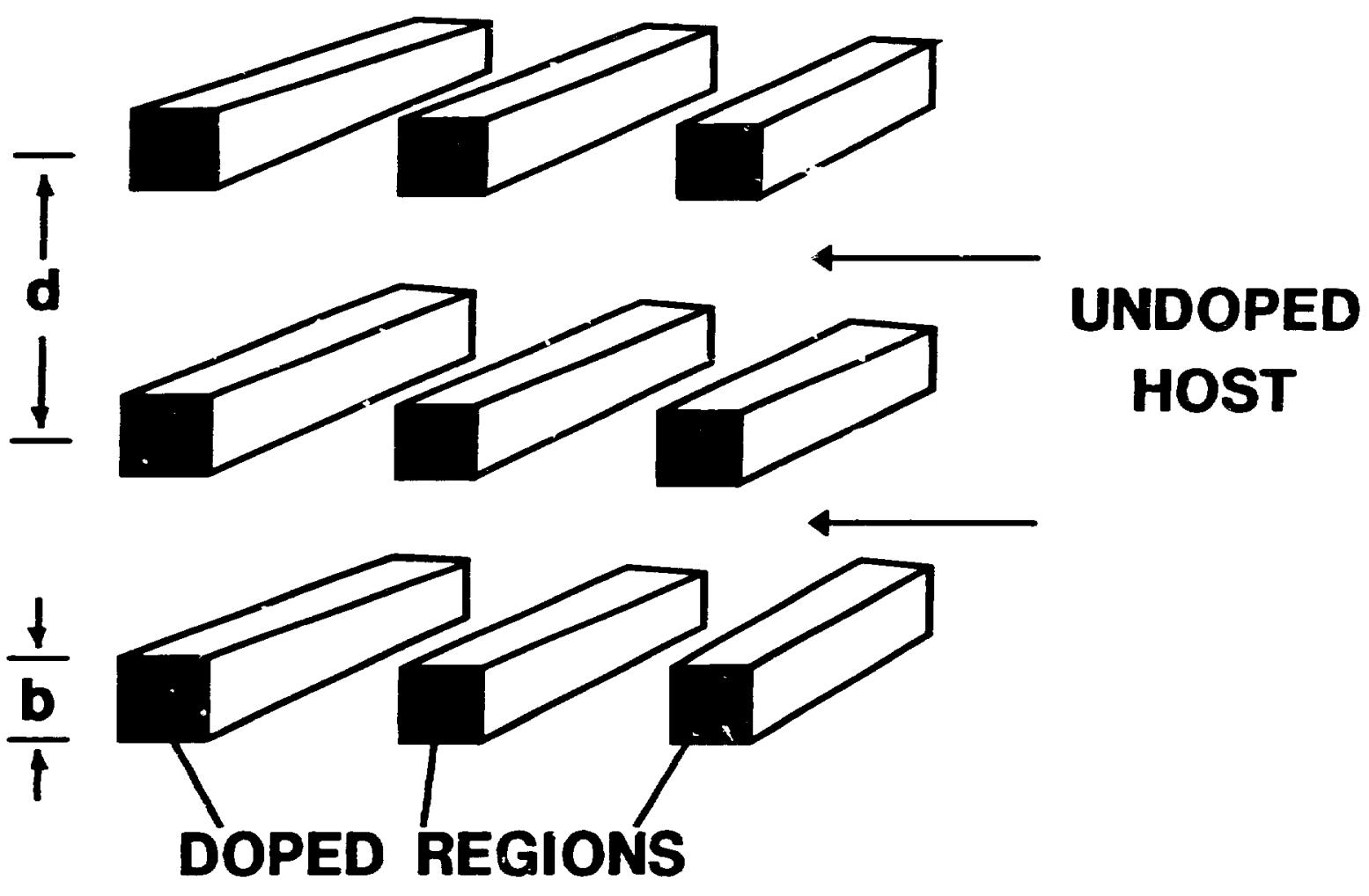

Los Alamos 


\section{INPUT WAVES $A_{i}=\operatorname{aexp}\left\{i\left(\underline{k}_{i} \cdot \underline{r}-\mathbf{w t} \pm \varphi\right)\right\}$}

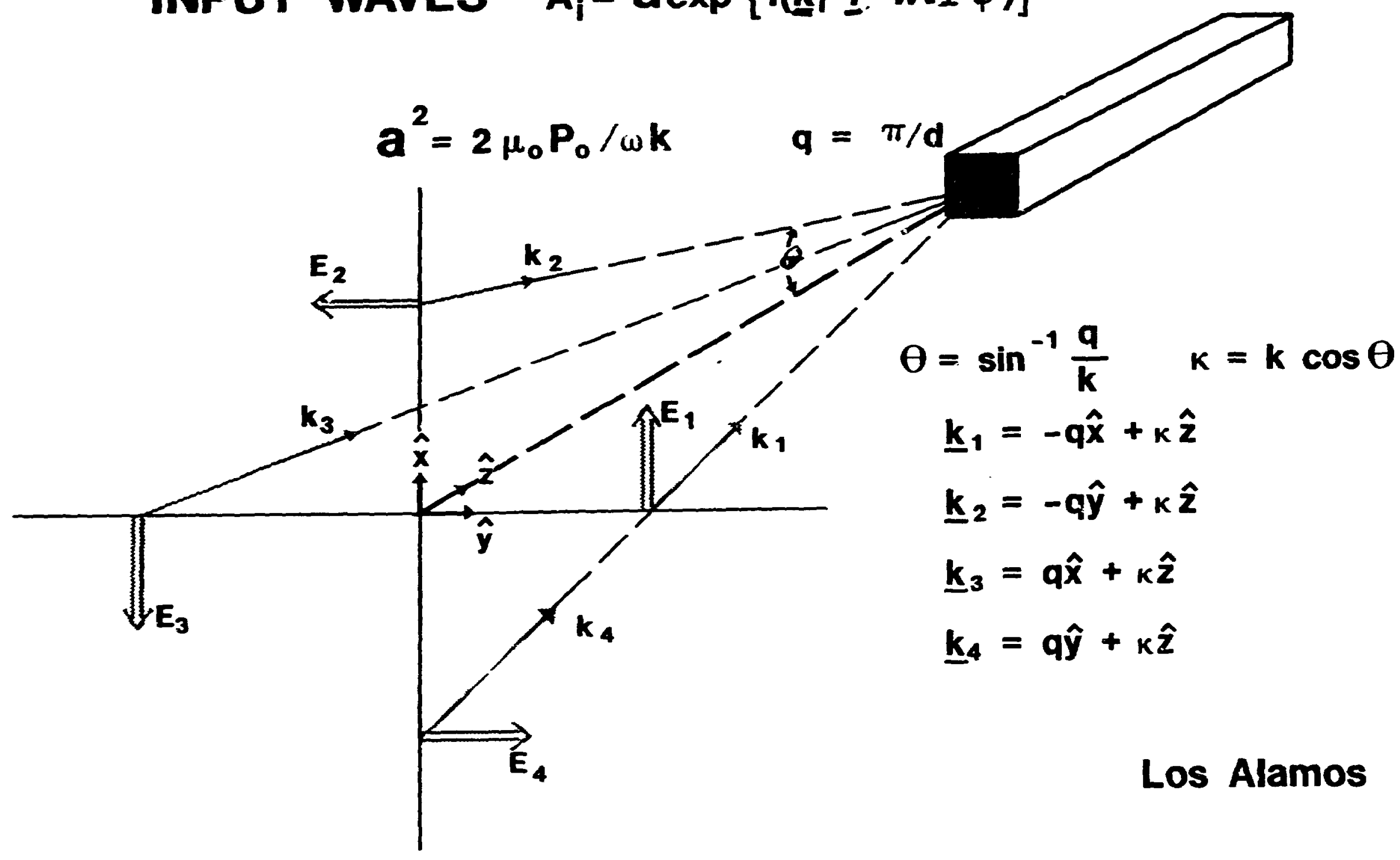


TEMPERATURE RISE

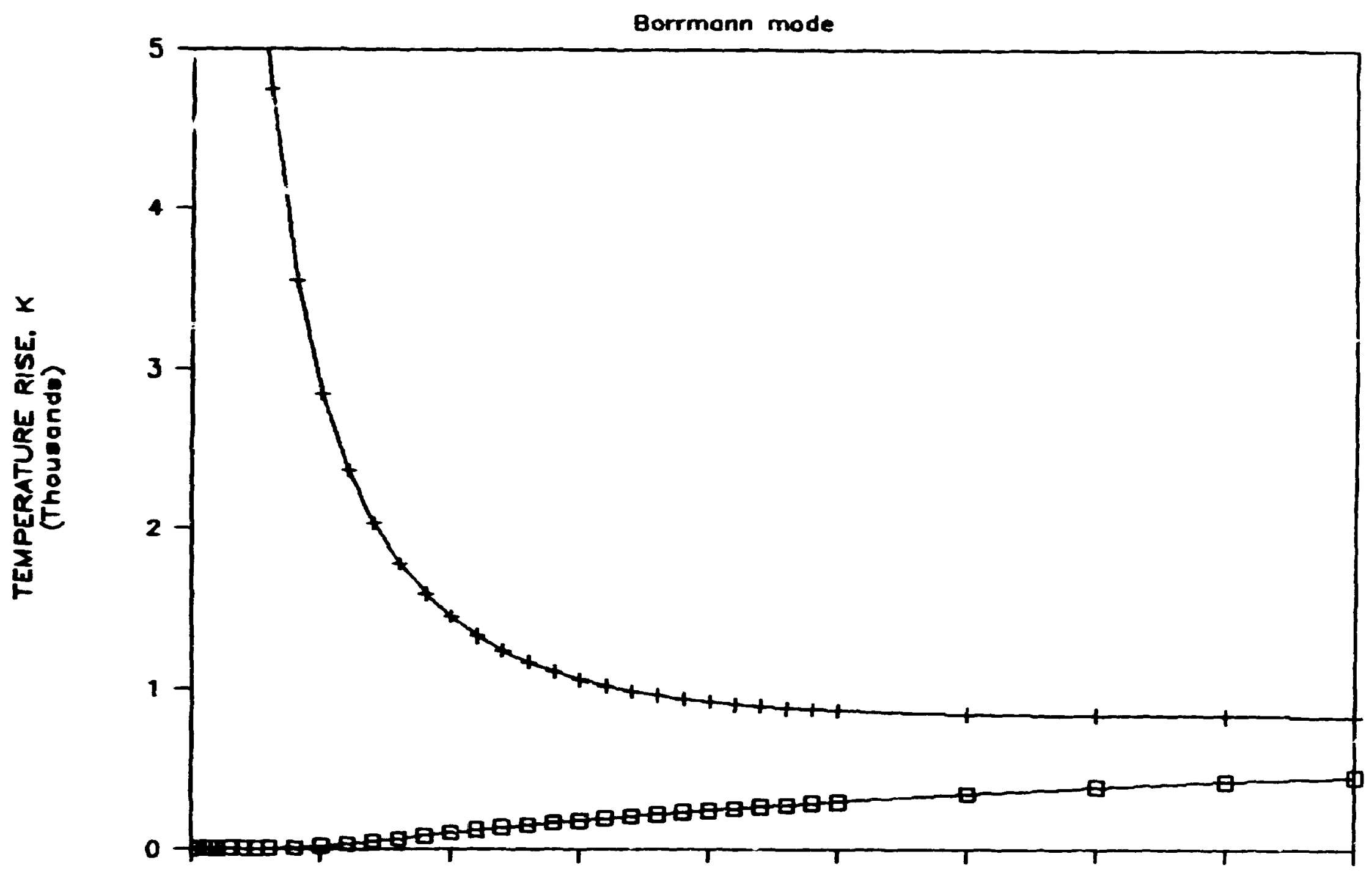




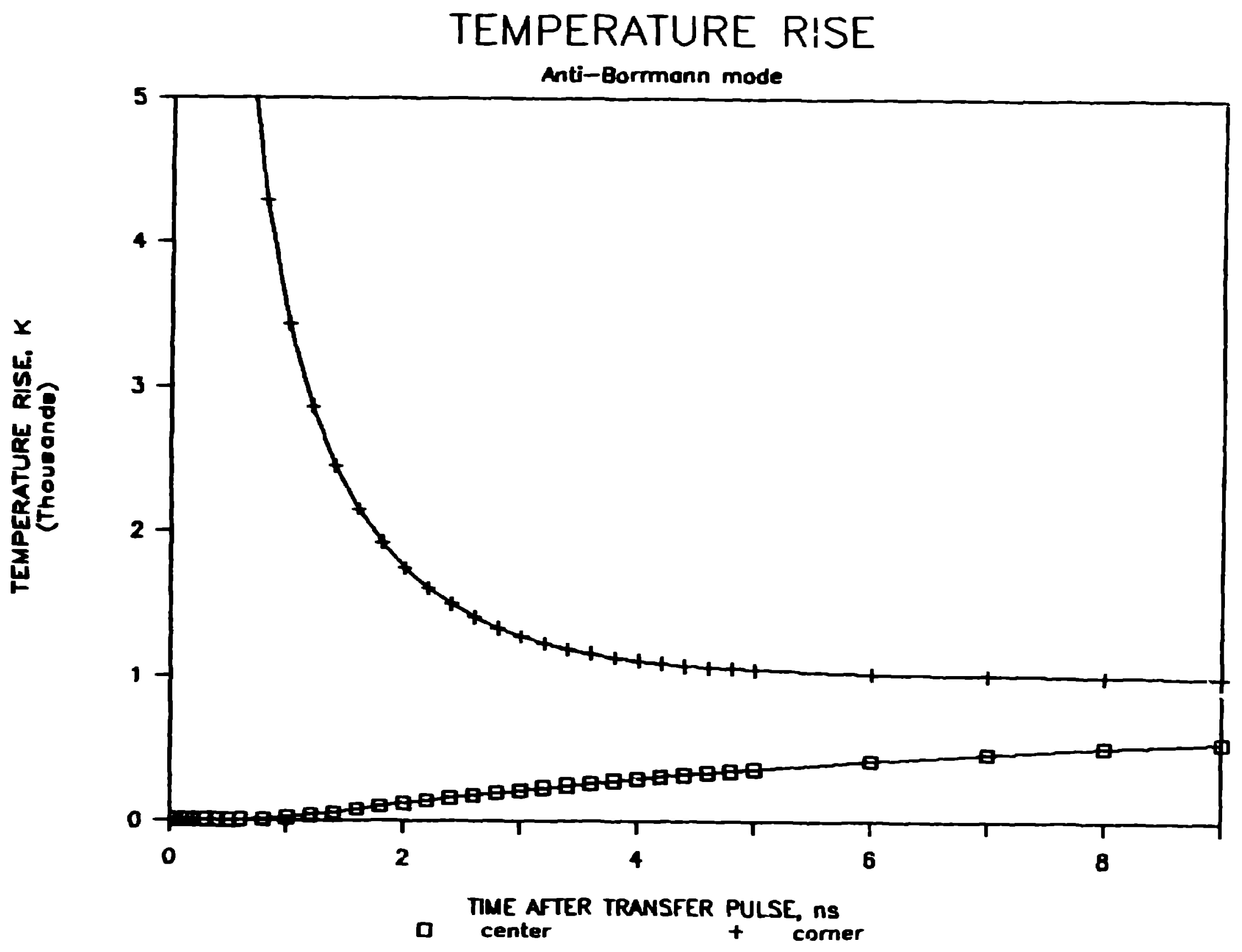




\section{TABLES}

I. Relationships of externally incident waves of transfer radiation to the internal wave modes created by four-wave Bragg reflections within a square superlattice.

2. Numerical values of the system's parameters that were assumed for the numerical exampla on which Figures 3 and 4 are based. 
INTERNAL WAVE MODES $q=\frac{\pi}{d}=k \sin \theta \quad k=k \cos \theta$

\begin{tabular}{|c|c|c|c|c|}
\hline FIELD & AMPLITUDE & WAVEFACTOR & ANTI-BORRMANN & BORRMANN \\
\hline $\begin{array}{l}E_{x} \\
E_{y} \\
E_{z}\end{array}$ & $\begin{array}{l}2 i \omega a \\
2 i \omega a \\
0\end{array}$ & & $\begin{array}{l}-\cos q y \\
\cos q x\end{array}$ & $\begin{array}{c}-\sin q y \\
\sin q x\end{array}$ \\
\hline $\begin{array}{l}\mathbf{B}_{\mathbf{x}} \\
\mathbf{B}_{\mathbf{y}} \\
\mathbf{B}_{\mathbf{z}}\end{array}$ & $\begin{array}{l}2 i \kappa a \\
2 i \kappa a \\
2 q a\end{array}$ & $\exp \{i(k z-\omega t)\}$ & $\begin{array}{c}\cos q x \\
-\cos q y \\
-\sin q x-\sin q y\end{array}$ & $\begin{array}{c}\sin q x \\
-\sin q y \\
\cos q x+\cos q y\end{array}$ \\
\hline $\mathbf{S}_{2}$ & $4 P_{0} \cos \theta$ & & $\cos ^{2} q x+\cos ^{2} q y$ & $\sin ^{2} q x+\sin ^{2} q y$ \\
\hline
\end{tabular}


CALCULATION OF TEMPERATURE RISE IN A SUPERLATTICE

\section{SUPERLATTICE PARAYETERS}

45.0 degrees Bragg angle of primary gamma radiation

n

$8-$

Order of Bragg reflection, transfer radiation

$\Lambda \quad 248.0 \mathrm{~nm} \quad$ Wavelength of transfer radiation

d $\quad 1.40 \mathrm{E}-06 \mathrm{~cm}$

Spacing of the doped regions (superlattice)

b $\quad 1.40 \mathrm{E}-07 \mathrm{~cm}$

Width of the doped reglons

THERYAL PARAYRTERS

$\begin{array}{ll}\kappa & 0.460 \mathrm{sq} . \mathrm{cm} / \mathrm{s} \\ \mu & 5.000 \text { per } \mathrm{cm} \\ C & 0.666 \mathrm{cal} / \mathrm{sq} . \mathrm{cm} * \mathrm{~K}\end{array}$

Thermal diffusivity of host

Energy absorption coefficlent of dopant

Thermal capacity of unit volume of host

TRANSFER PULSE PARAYETERS

\begin{tabular}{|c|c|c|c|}
\hline & A-MODE & B-MODE & \\
\hline & 1.9836 & 0.0164 & Mode Eactor \\
\hline$\Delta t$ & $1.000 \mathrm{E}-12$ & $1.00 \mathrm{E}-12$ & Duration of transfer pulse, s \\
\hline $\mathbf{P}$ & $1.000 E+16$ & $1.00 \mathrm{E}+18$ & $\begin{array}{l}\text { Powor flux of each transfer beam, } \\
\text { W/oq. sm }\end{array}$ \\
\hline Q & $5.52 E-05$ & $4.58 E-05$ & $\begin{array}{l}\text { Hoat created por unit length of } \\
\text { dopant, } J / \mathrm{cm}\end{array}$ \\
\hline
\end{tabular}


GRASER SUPERLATTICE

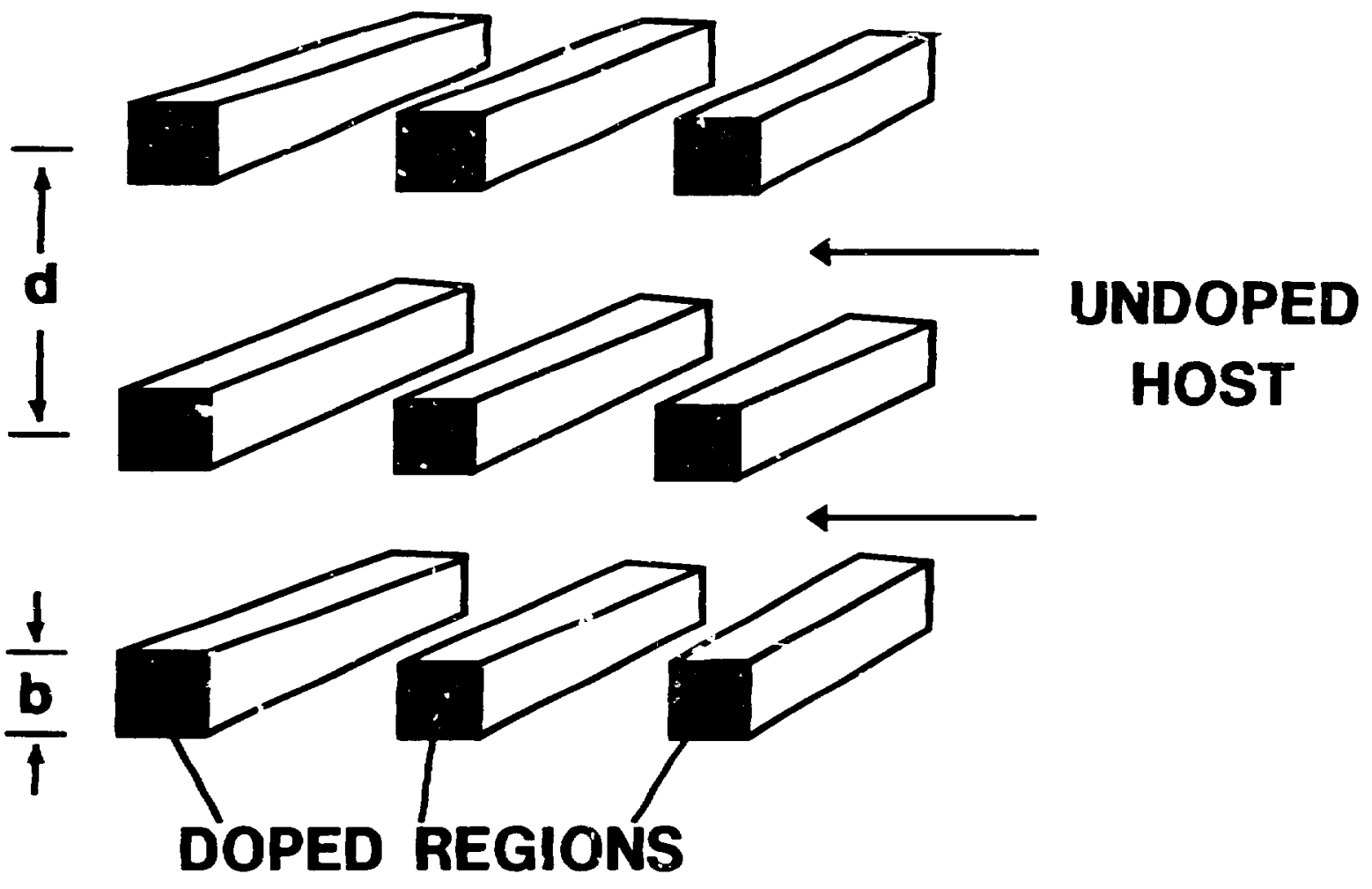

Los Alamos 
INPUT WAVES $\mathbf{A}_{\mathbf{i}}=\mathbf{a} \exp \{i(\underline{\mathbf{k}}, \cdot \underline{\mathbf{r}}-\mathbf{w t} \pm \varphi)\}$

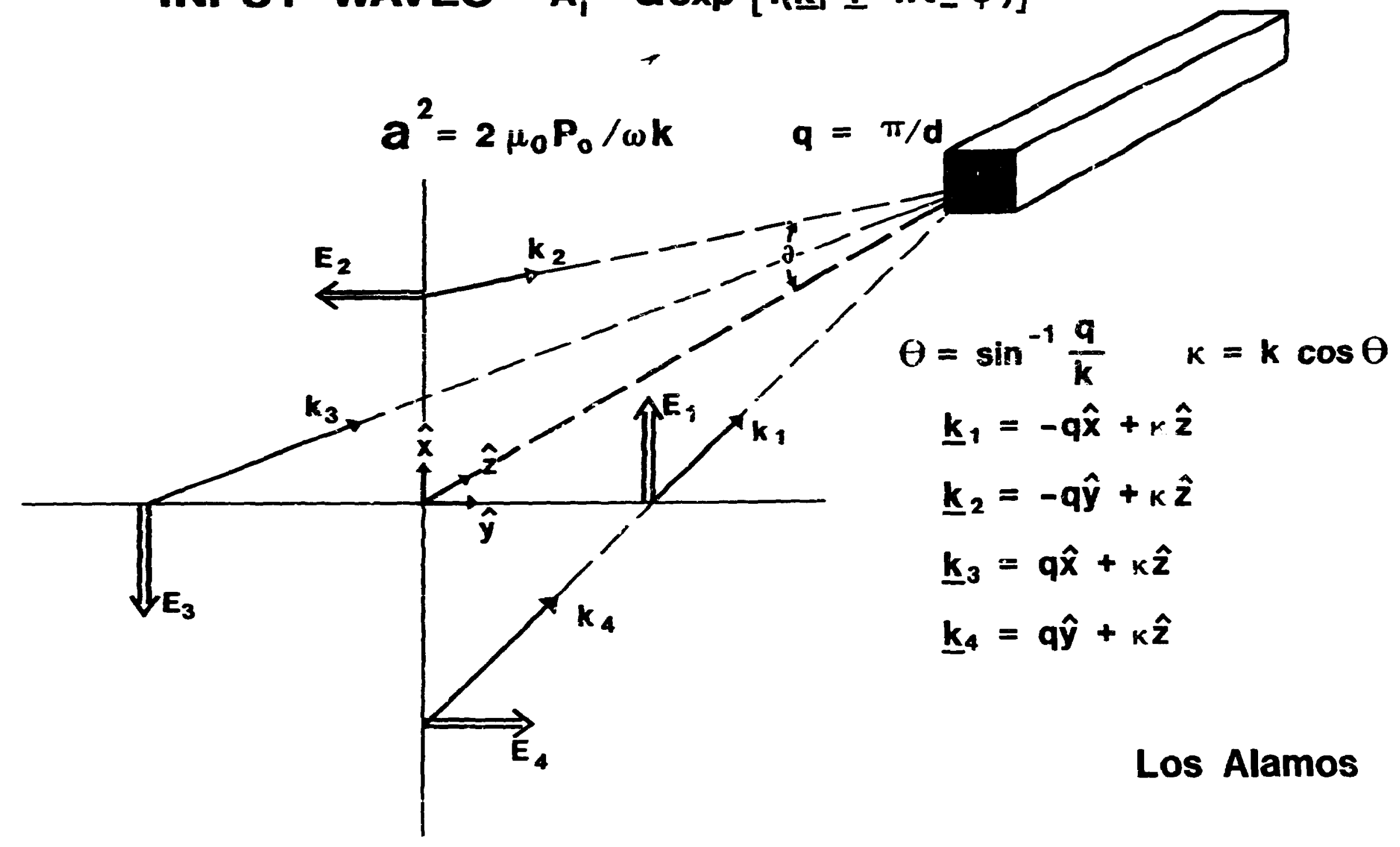

